\title{
Prosody and punctuation in The Stranger by Albert Camus
}

Mari Lehtinen

Department of Romance Languages, University of Helsinki, Finland

https://doi.org/10.36505/ExLing-2006/01/0036/000036

\begin{abstract}
The aim of this paper is to provide an overview of a study concerning the prosodic interpretation of punctuation. The focus is placed on the two most common punctuation marks, i.e., full stops and commas. The findings are based on a comparison between The Stranger by Albert Camus the way it is published as a book and the way it is read out by its author in two French radio broadcasts in 1954. My findings suggest that the oral interpretation of the punctuation clearly is subject to a certain code. However, the most interesting findings concern a non-negligible number of cases in which the code is not observed.
\end{abstract}

\section{Introduction}

The relationship between the spoken and the written languages constitutes one of the eternal questions repeatedly taken up in different fields of linguistics as well as within other disciplines. This paper approaches the question in the perspective of oral equivalencies of written punctuation marks. For this purpose, I have chosen to study The Stranger (L'étranger) by Albert Camus. The data concerning the punctuation comes from a French edition of the book, published by Gallimard in Paris in 1996 ( $1^{\text {st }}$ edition: 1942). The prosodic findings in turn are based on two French radio broadcasts in which Camus himself reads out the first half of the volume. The broadcasts were recorded and transmitted by La Radiodiffusion française (RDF) in 1954. The length of the reading time examined for this paper is 87 minutes, which corresponds to six chapters or 95 pages of the text. These pages include 2309 punctuation marks. The number consists of full stops, commas, question marks, exclamation points, colons, dashes, semicolons, points of suspension and parentheses. Because of the limited number of pages available, only the occurrences of full stops and commas are taken into consideration in this paper; these two marks cover together about $94 \%$ of the total number of punctuation marks in my corpus. Each occurrence has been analysed both melodically and rhythmically. The prosodic analyses have been carried out with the help of the computer programs Sound Forge and Praat.

According to my findings, full stops tend to be read out with a pitch fall followed by a pause, whereas commas rather entail a pitch rise instead of a fall. This might not seem surprising. But it is interesting to notice that there

ExLing 2006: Proceedings of 1st Tutorial and Research Workshop on Experimental Linguistics, 28-30 August 2006, Athens, Greece 
also are a certain number of cases in which full stops and commas are 1) interpreted melodically the opposite way compared with their prototypical oral equivalent, 2) interpreted melodically in the standard manner but passed by without a pause, that is to say, ignored from the rhythmical point of view, 3) interpreted melodically the opposite way with regard to the prototype and in addition to that, without a pause, 4) melodically ignored, that is to say, passed over without any noticeable pitch change, or 5) ignored both melodically and rhythmically, that is to say, passed by without a pitch change or a pause.

The atypical prosodic interpretations of punctuation marks have as a result a prominent intonation the functions of which often seem to be similar to those of certain prosodic contextualisation phenomena of speech: their occurrences often seem to be related to stylistic and discourse-structuring factors that, in turn, contribute to the construction of an interpretational framework for what is being said.

\section{Prosodic interpretation of full stops and commas. Prototypes and atypical cases}

In this chapter, I will briefly present some general observations and hypotheses concerning different prosodic interpretations of full stops and commas. However, for lack of space, only an overall description of some general aspects can be provided in the current paper: unfortunately examples cannot be given and only the prototypical prosodic equivalent as well as the most common atypical interpretation of each of the two punctuation marks can be treated.

\section{Prototypical interpretations}

As it could be expected, the full stop is the most common punctuation mark in the corpus: it occurs 1185 times and thus covers over $50 \%$ of all punctuation. In $79 \%$ of the cases full stops are interpreted with a remarkable pitch fall associated with a clearly perceptible pause. This seems natural, because as it is largely known, a pitch fall typically indicates conclusion in spoken French ( $c f$. references), whereas a full stop basically finishes an autonomous whole in written language (e.g. Catach 1996). The prototypic functions of a pitch fall and a full stop thus seem similar both syntactically and semantically with respect to their concluding nature. Concerning the pause, which is the second constituent of the prototype, it is known that when its occurrence is related to discourse-structuring, it gives the listener the time required to construct the meaning of the preceding unit (Morel \& Danon-Boileau 1998). The functions of a pause are thus consistent with those of a pitch fall and a 
full stop (when a pause is used as a discourse-structuring marker, which is obviously not always the case; a pause can also be related to utterance-formulation processes, lexical research, stylistic factors, etc.). According to my findings, when a full stop is interpreted in this prototypical manner, it gives an independent position to the action described in the sentence that it concludes. It also "closes" the situation in a way; that is to say, it does not create expectations about any other relevant situational factors but rather presents the sentence as an exhaustive description of the action.

In $64 \%$ of the cases examined a comma entails a rising pitch combined with a clearly perceivable pause. A comma is typically used to structure the syntactic and semantic whole formed by a sentence by separating its constituents (Catach 1996). As a comma always occurs inside a sentence and not at the end of it, its functions are generally not concluding, but, on the contrary, continuative. In regard to this aspect of continuity, the role of a comma thus seems in some measure analogous with that of a pitch rise in French speech ( $c f$. references).

It is important to note that especially in languages like French in which the use of a comma is not subject to strict rules (unlike in Finnish, for example), the structuring functions of the mark do not reflect only the syntax of the sentence but also, for instance, its internal informational relationships as well as the stylistic choices of the author. In the light of my findings, it is frequent that when two or more separate acts are described in consecutive clauses within one sentence so that each clause is finished by a comma interpreted in the prototypical manner, the rising pitch emphasizes the situational dependence and closeness of the acts which are being described; often a full stop and / or a falling pitch between the clauses would mark too big an independence and temporal distance between the acts.

\section{Most common atypical interpretations}

Although most of the full stops occurring in my corpus entail a falling pitch and a pause, it is, nevertheless, interesting to observe that $14 \%$ of them are interpreted by the speaker with a remarkable pitch rise followed by a pause. In these cases, the prosodic interpretation is not analogous with the prototypical use of a full stop, but it is rather reminiscent of that of a comma. Accordingly, it seems that when a full stop is interpreted with a pitch rise instead of a fall, it indicates structural and situational continuity. All cases of this kind naturally occur inside a textual paragraph.

Generally speaking, a rising pitch seems to serve as a link between two or more clauses or sentences that describe acts or circumstances that are temporally and spatially closely related to each other. The difference between full stops and commas in this respect is that commas interpreted with 
a rising pitch most often separate acts or circumstances that are simultaneous or nearly simultaneous, whereas those separated by full stops are consecutive: clauses distinguished by "rising commas" typically refer to a same situation, whereas sentences concerned by "rising full stops" rather form a continuum of closely related situations. In both cases, the rising pitch anticipates activity; it creates an interpretational framework for an active situation.

As already mentioned above, when a full stop is interpreted in the prototypical manner, it normally indicates finality and autonomy. Analogously, when a comma is interpreted with a pitch fall and a pause (6\% of the cases), it loses its continuative value. The difference between full stops and commas in this regard is that the concluding effect of a comma is weaker than that of a full stop: where a full stop implies finality and autonomy, a comma implies stagnation. Often commas entailing a falling pitch and a pause occur in "passive" contexts, such as descriptions of the milieu. In cases of this kind, the pitch falls have a stylistic function: they typically convey a nuance of coldness and of informational irrelevance and contribute to contextualise the contents of the sentence in question as a mere description of circumstances, and not, for example, as a meaningful event.

\section{References (selection)}

Catach, N. 1996. [1994]. La ponctuation. Paris, PUF.

Delattre, P. 1966. Les dix intonations de base du français. French Review XL (I), 114.

Di Cristo, A. 1998. Intonation in French. In Hirst, D. and Di Cristo, A. (eds.) 1998, Intonation Systems. A Survey of Twenty Languages, 195-218. Cambridge, Cambridge University Press.

Fónagy, I. and Fónagy, J. 1983. L'intonation et l'organisation du discours. BSLP 78, $1,161-209$

Morel, M.-A. and Danon-Boileau, L. 1998. Grammaire de l'intonation. L'exemple du français oral. Paris / Gap, Ophrys.

Rossi, M. 1999. L'intonation, le système du français : description et modélisation. Paris / Gap, Ophrys. 